\title{
EU, PROFESSOR DO MUNDO: A INTERCULTURALIDADE E AS PRÁTICAS REFLEXIVAS DE PROFESSORES DE LÍNGUAS DO UnB IDIOMAS
}

\author{
Me, world teacher: interculturalism and reflexive practices of language teachers from \\ UnB IDIOMAS
}

\author{
Carla Mary Silva Eloy,SEEDF ${ }^{1}$ \\ Eduardo Dias da Silva, SEEDF ${ }^{2}$
}

\begin{abstract}
RESUMO: Por meio de uma análise documental, apresentamos, nesta pesquisa qualitativa, um recorte do trabalho desenvolvido pelos profissionais de linguagem, nativos e não nativos do Centro Universitário de Línguas da Universidade de Brasília (Programa Permanente de Extensão - UnB Idiomas), com o intuito de observar qual o entendimento que eles têm a respeito da interculturalidade e também se os aspectos socioculturais integram suas práticas reflexivas no ambiente escolar como elementos essenciais para o ensino-aprendizagem de línguas estrangeiras (LE), tendo como base o período de 2010-2014. Após análises dos relatórios finais dos cursos, percebemos que tanto o entendimento como a prática dos profissionais analisados refletem o trabalho/pesquisa desenvolvido ao longo do período pelos supervisores acadêmicos do UnB Idiomas no que tange à formação continuada e em grupo e quanto às observações e discussões coletivas, visando não só o melhoramento do Programa como também o aperfeiçoamento dos profissionais de LE do UnB Idiomas.
\end{abstract}

PALAVRAS-CHAVE: Interculturalidade; Práticas reflexivas; UnB Idiomas; Línguas Estrangeiras

ABSTRACT: In this qualitative documental analysis, we present a side view of the language professionals, being native or not, from the University Language Center at the University of Brasília (UnB Idiomas). We aim at the understanding of interculturality and reflexive practices in the school environment as essential elements for the teaching and the learning foreign languages (FL), in $n$ the period 2010-2014. After the analysis of the final course reports, we realized that both the understanding and the practice of the professionals investigated reflect the work/research developed during the period by the academic supervisors of UnB Idiomas in relation to the continuous formation and to the group, as well as the observations and group discussions, focusing not only on the improvement of the program but also on the improvement of the professionals of FL at UnB Idiomas.

KEYWORDS: Interculturality; Reflective Practice; UnB Idiomas; Foreign languages

\section{INTRODUÇÃO}

Como supervisores pedagógicos de um dos maiores centros universitários de línguas estrangeiras (LE) do Centro-Oeste (Programa Permanente de Extensão UnB Idiomas da

\footnotetext{
${ }^{1}$ Mestra em Linguística Aplicada pela Universidade de Brasília. Professora de Educação Básica na Secretaria de Estado de Educação do Distrito Federal (SEEDF). Pesquisadora do GECAL/UnB/CNPq e Supervisora Acadêmica do PPE/UnB Idiomas. carlaeloy@hotmail.com

${ }^{2}$ Doutorando em Literatura e Mestre em Linguística Aplicada pela Universidade de Brasília. Pedagogo e Professor de Educação Básica na SEEDF, Pesquisador nos grupos GECAL/UnB/CNPq e no FORPROLL/UFVJM/CNPq. edu_france2004@yahoo.fr
} 
Universidade de Brasília, doravante UnB - Idiomas), como professores de língua estrangeira (LE) com anos de experiência na rede pública e privada, e com incessantes esforços na consolidação de uma práxis pedagógica crítico-reflexiva, nos foi possível perceber a importância da Cultura no ensino-aprendizagem de LE, bem como seu reflexo na formação de professores. Entendemos que, ambas, língua e cultura, se apresentam como um todo indissociável "porque a todo ato de língua subjaz um ato de cultura e porque todo ato de língua se estrutura em função de uma dimensão social e cultural” (DÍAZ, 2005, p. 838, tradução nossa).

Neste estudo qualitativo de análise documental (ANDRÉ, 2005), propomos uma análise dos relatórios finais de cursos livres de LE ministrados para a comunidade interna e externa da Universidade de Brasília (UnB), ofertados pelo UnB Idiomas ${ }^{3}$. Como recorte de pesquisa, temos como amostra aleatória, no mínimo, 2 professores (nativos e não-nativo) por LE (francês, inglês, espanhol, mandarim, italiano, alemão, russo, japonês, hebraico, coreano, árabe, turco, esperanto), no período de 2010-2014.

Entendemos, também, que a sala de aula é o lugar em que deve ocorrer a sensibilização em relação ao relativismo e à variação cultural, iniciando, assim, um processo de descobrimento e de autodescobrimento que parta do próprio contato cultural inerente a todo o ambiente escolar de LE. Concordamos com Byram $(1997$; 2008) ao propôr cinco capacidades formadoras da competência intercultural necessárias para uma comunicação exitosa, que serão apresentadas mais adiante, quando ele ao afirmar que a última capacidade - a de adquirir uma consciência cultural crítica - deve ser ensinada em um contexto de sala de aula por ser o ambiente no qual se pode adquirir conhecimentos sobre os processos de interação intercultural.

E, nesse entendimento, nos perguntamos se nossos professores de idiomas (nativos ou não) entendem a língua como cultura e transferem isso para sua práxis pedagógica, e se (re)transmitem conhecimentos referentes à própria língua (à sua estrutura) tendo como base aspectos culturais.

Essa pesquisa nasce em decorrência de nosso empenho em responder ou clarificar nossas indagações. Nela, a comunicação intercultural foi o primeiro aspecto abordado - se tracejou um delineamento acerca dos significados da comunicação intercultural,

\footnotetext{
${ }^{3}$ Gostaríamos de externalizar nossos agradecimentos à Universidade de Brasília (UnB), ao Instituto de Letras (IL), ao Departamento de Línguas Estrangeiras (LET) e ao Programa Permanente de Extensão da Universidade de Brasília (PPE/UnB - Idiomas) e principalmente aos professores de LE que, gentilmente, aceitaram participar dessa pesquisa.
} 
principalmente daqueles relacionados ao ensino-aprendizagem de LE. Nessa oportunidade, foram realizadas breves conceituações sobre língua, cultura e comunicação, igualmente retratadas sob a luz do ensino-aprendizagem de línguas, tendo como suporte teórico Díaz (2005), Byram (1997; 2008), Elhajji (2006), Hall (1978), entre outros. O subsequente assunto diz respeito à formação continuada dentro da competência profissional e às práticas reflexivas dos professores como meio transformador de sua realidade e dos seus alunos.

As perguntas supracitadas que norteiam esta pesquisa qualitativa de análise documental - leituras de relatórios finais de cursos livres de línguas - podem desmembrar-se em: a) qual (quais) as percepções sobre interculturalidade dos professores de línguas do UnB - Idiomas?; b) e como essas reflexões orientam as práticas desses professores?

No tocante às características básicas da metodologia aplicada a esta pesquisa qualitativa de análise documental - Moreira (2002) as apresenta por meio de um sumário contendo seis itens, os quais não pretendemos esgotar. Para ele, a pesquisa qualitativa de modalidade documental inclui: 1) a interpretação como foco. Nesse sentido, há um interesse em interpretar a situação em estudo sob o olhar dos próprios participantes, via leitura dos relatórios finais dos cursos livres; 2) a subjetividade é enfatizada. Assim, o foco de interesse é a perspectiva dos informantes; 3) a flexibilidade na conduta do estudo. Não há uma definição a priori das situações; 4) o interesse é no processo e não no resultado. Segue-se uma orientação que objetiva entender a situação em análise; 5) o contexto como intimamente ligado ao comportamento das pessoas na formação da experiência; e 6) o reconhecimento de que há uma influência da pesquisa sobre a situação, admitindo-se que o pesquisador também sofre influência da situação de pesquisa.

Tencionamos, ao lançar mão da análise conforme proposta nesta pesquisa, verificar se os professores de LE do UnB Idiomas reconhecem - ou não - a importância dos elementos socioculturais no processo de ensino-aprendizagem de LE e se essas reflexões orientam sua práxis pedagógica. Logo, por meio dos resultados desta investigação, almejamos apontar a importância de se fornecer oportunidades para que os professores de LE possam conhecer, empregar e refletir sobre suas ações em situações de interações comunicativas interculturais em sala de aula.

Convém ressaltar que não pretendemos, em hipótese alguma, esgotar todas as possibilidades de pesquisa que envolve os construtos supracitados seja na área da Linguística Aplicada (Crítica) ou na área da Educação ou ciências afins. 


\section{COMUNICAÇÃO INTERCULTURAL}

A prática da comunicação intercultural vem atravessando numerosas e substanciais transformações ao longo dos anos. Na época atual, os encontros culturais têm um alcance quase ilimitado, abarcam um número mais expressivo de pessoas e são mais complexos em sua natureza. Isso se evidencia na atual paisagem mundial em que a distância espacial e temporal está diminuindo e as fronteiras estão desaparecendo.

Essa nova realidade indica que as vidas culturais das pessoas no mundo estão mais intensamente interligadas. Um exemplo concreto é a massiva profusão do uso da comunicação eletrônica que está conduzindo os preceitos da economia, assim como as identidades culturais e linguísticas.

Nessa perspectiva, Elhajji (2006) aponta que a particularidade desta época contemporânea reside na rearticulação das relações sociais e de produção em torno das novas tecnologias de comunicação. Ele discorre também sobre o conceito de globalização, sugerindo que este deve ser entendido como a globalização de uma ação ou de um processo, ou seja, sua realização ou sua vivência simultânea em múltiplos pontos do espaço (2006, p. $3)$.

Ainda segundo este autor, ao mesmo tempo em que se experimenta a globalização de certos aspectos das culturas locais, se vivencia o processo no qual as identidades étnicas e culturais se tornam o verdadeiro catalisador da história. Nesse sentido, o mesmo autor afirma que uma das vantagens da comunicação intercultural, portanto, é a de dotar a sociedade de interfaces comunicacionais que possibilitem uma maior transparência dos processos sociais, políticos e culturais, evitando, assim, suspeitas infundadas e preconceitos disfarçados. Ele conclui ressaltando que a comunicação intercultural constitui "uma esfera social, política, discursiva, epistemológica e cognitiva que merece especial atenção por parte dos estudos da comunicação, como de todas as áreas das ciências humanas e sociais" (ELHAJJI, 2006, p. 12).

Entende-se, portanto, que a comunicação intercultural caminha e deve caminhar, imprescindivelmente, paralela ao ensino-aprendizagem de línguas estrangeiras, uma vez que a sociedade contemporânea parece exigir que, cada vez mais, se reconheça a obrigatoriedade de preparar os atores sociais para que atuem adequadamente em contextos interculturais.

Nesse âmbito, evidencia-se que e como a compreensão da ação da cultura na comunicação pode melhorar a habilidade para interatuar em um mundo cada vez mais interdependente. É o papel das línguas estrangeiras cobrando uma identidade ainda mais 
destacada no tocante à sua dimensão de corresponsabilidade social na construção dessa perspectiva intercultural.

Para Vez (2005), a dimensão intercultural integra e potencializa a tomada de consciência sobre o papel da língua estrangeira como instrumento social que proporciona aos aprendizes a oportunidade de desenvolver suas capacidades como experimentadores e negociadores mais do que como meros receptores passivos de dados.

Oportunamente o conceito de intercultural vem sendo desenvolvido a partir da perspectiva da aproximação entre língua e cultura no processo de ensino-aprendizagem de língua estrangeira. Trata-se de uma espécie de mediação cultural na qual o aprendiz participa e, ao mesmo tempo, reflete sobre sua cultura e sobre a cultura-alvo. Por esse ângulo, Byram (1997; 2008), ao discorrer sobre a competência comunicativa intercultural, interpretada por Díaz (2002; 2005), a interpreta como sendo a capacidade cognitiva e afetiva de estabelecer e manter relações interculturais e de estabilizar a própria identidade pessoal enquanto mediada entre culturas:

Quando uma pessoa aprende uma língua estrangeira, se enfrenta diferentes interpretações de muitos dos valores, normas, comportamentos e crenças que havia adquirido como naturais e normais. A Competência Intercultural é, pois, a habilidade de poder se desenvolver nesse tipo de situações, com contradições e diferenças (DÍAZ, 2002, p. 201, tradução nossa).

O termo competência intercultural surge, portanto, com o firme propósito de salientar que, em um encontro intercultural, põe-se em funcionamento a competência comunicativa dos interlocutores. Nasce, por consequência disso, o conceito falante intercultural - "um indivíduo enfrentando situações de choque cultural, mas que deve compreender as relações entre culturas e saber mediar entre formas distintas de viver e interpretar o mundo" (KRAMSCH, 2009, p. 23). Ainda segundo essa autora:

\footnotetext{
O que caracteriza um competente usuário de um idioma não é a capacidade de falar e escrever segundo as regras da academia, e sim, a adaptabilidade na hora de selecionar formas corretas e apropriadas exigidas pelo contexto social. Essa forma de competência é precisamente a do falante intercultural que opera nas fronteiras que dividem vários idiomas, manobrando sua trajetória pelas turbulentas águas dos mal-entendidos culturais (KRAMSCH, 2001, p. 37, tradução nossa).
}

Nessa perspectiva e retomando o binômio língua e cultura, vê-se que a cultura afeta a forma como se envia e se "constrói" a mensagem, como se recebe e a forma de interpretá-la. Assim, para que haja comunicação, a cultura propicia o contexto adequado. Da mesma forma, uma cultura não pode sobreviver sem a comunicação, pois depende dela para sua iniciação, manutenção, transformação e transmissão. 
Isso posto, a cultura é, por si própria, um sistema de comunicação. Como observado por Hall (1978, p. 37), “cultura é comunicação e se manifesta no processo da comunicação intercultural" - e a cultura se encerra em um conceito triádico. Ainda no que tange à discussão sobre cultura, o comunicólogo Loenhoff (1992) a constitui com base em suas três funções: cultura como condição da comunicação, cultura como resultado da comunicação e cultura como constituída dentro da prática comunicativa".

Ainda que não seja nossa pretensão apresentar ou relacionar a abrangente dimensão que circunda o conceito de cultura, é importante esclarecer que, no decurso deste texto, as ocorrências desse conceito foram apresentadas a partir das definições constantes da literatura na atualidade sobre o ensino-aprendizagem de línguas estrangeiras. Tal qual apresenta Miguel (2008) na obra Vademécum - Para formação de professores, na qual afirma que "cultura é o substrato que faz com que os falantes de uma língua entendam o mundo, ajam sobre ele e interajam comunicativamente de um modo culturalmente parecido", portanto, cultura é vista como parte da competência comunicativa, ou seja, é componente necessário para o êxito comunicativo.

Para língua, nos apropriamos da definição de Díaz (2002; 2005), presente no mesmo volume, o qual alcunha o termo língua como um sistema de ação social que engloba significados culturais:

O termo 'língua' não vai se referir somente aos elementos de ordem linguística, mas
também a todo um sistema de ação social que conduz a significados culturais: um
código cultural, um modo de interpretar a realidade, um nível de cultura subjacente
que, em uma perspectiva de regras de comportamento e pensamento, determinam a
forma em que os indivíduos definem seus valores, estabelecem suas cadências e
ritmos de vida fundamentais; trata-se de uma 'gramática cultural' oculta que, se não é
dominada, dá lugar na comunicação a casos de incompreensão, conflito, choques
culturais e mal entendidos. Fica evidente que a simples aquisição do sistema
linguístico não assegura a compreensão, razão pela qual não é possível dissociar no
plano de comunicação a língua da realidade que subjaz, ou seja, da bagagem cultural:
a cultura. Língua e cultura nos são apresentadas como um todo indissociável, porque
a todo fator linguístico subjaz um fator cultural e porque todo fator linguístico se
estrutura em função de uma dimensão social e cultural (DÍAZ, 2002, p. 220, tradução
nossa).

Nessa definição sobressai, oportunamente, a ideia da ação social como sinônimo de ação comunicativa e como sendo lugar de encontro primordial entre o linguístico e o cultural, entre a língua e a cultura de uma comunidade. Além disso, manifestam-se as consequências do ensino de uma língua estrangeira descontextualizada da realidade cultural das comunidades que a utilizam como instrumento de comunicação. Ou, dito de outra forma, a definição acima deixa claro que, tentar ensinar uma língua de um modo culturalmente 
descontextualizado, é um empreendimento que está, inevitavelmente, condenado ao inadequado ou que somente contempla os aspectos estruturais.

De igual modo à noção de comunicação, adotamos o entendimento de Sapir (1954; 1971), em razão de que para ele a comunicação é a maior força de socialização que existe, dado que a sociedade não só continua a existir pela comunicação, mas na comunicação. Ainda segundo esse autor, a comunicação constitui um processo ou forma de interação que é interpessoal e que só se pode dizer completo no momento em que resulta em alguma espécie de compreensão. Para ele, a função social da comunicação parece ser a de dar origem e manter o entendimento e a solidariedade cultural entre os indivíduos e sociedades.

Assim sendo, a comunicação opera em duas dimensões. De um lado, serve para provocar uma difusão de traços culturais, ampliando, assim, a área cultural dentro da qual são possíveis as relações sociais. De outro, a comunicação, na medida em que engloba as influências culturais diversas, tende a introduzir novas ideias que inevitavelmente aparecem no processo de aculturação, isto é, de transformação dos próprios elementos culturais (SAPIR, 1954).

Apresentadas as oportunas relações entre cultura, língua e comunicação, convém observar que o conceito de comunicação intercultural mantém uma relação dialógica com o ensino-aprendizagem de línguas, o que promove, consequentemente, um sentido de via dupla: enquanto os estudantes de língua estrangeira desenvolvem sua competência comunicativa por meio da comunicação intercultural, especialistas do campo da cultura se fortalecem com as metodologias usadas por estes no ensino-aprendizagem de línguas. Como expressa Rivers:

Porque grande parte de outra cultura é expressa dentro e através da língua, os alunos de uma língua estrangeira apresentam-se em posição privilegiada para penetrar a cultura em profundidade, muito mais que aqueles que a veem somente pelos relatos em sua própria língua. Os aprendizes de uma segunda língua são mais capazes de reviver as experiências de uma cultura emocional e intelectualmente (RIVERS, 1983, p. 173, tradução nossa).

A essa altura, é possível afirmar que já nos encontramos completamente aptos para sermos devidamente apresentados ao conceito de comunicação intercultural sob o viés de diferentes autores. Assim sendo, a seguir, passamos a apresentar alguns desses pontos de vista.

Gudykunst (2002), por exemplo, entende a comunicação intercultural como o processo de interação simbólica que inclui indivíduos de diferentes culturas reconhecíveis nas 
percepções e nas formas de conduta, de tal maneira que essas variações afetarão significativamente a forma e o resultado do encontro.

Bennett $(2013 ; 1986 ; 1998)$, a sua vez, concebe o conceito de comunicação intercultural como a interação que ocorre quando o enunciado de um membro de determinada cultura deve ser recebido, interpretado e compreendido por outro indivíduo pertencente a uma cultura diferente. Assim, os participantes de um encontro intercultural interagem, apoiando-se em suposições culturais próprias e, quanto mais componentes culturais forem compartilhados, mais facilitada será a comunicação entre eles.

Para Samovar e Porter (1972; 1998), entre os vários termos existentes nas ciências da linguagem para se referir à comunicação intercultural, como cross-cultural, transcultural, inter-racial etc., o termo comunicação intercultural é o mais conveniente, uma vez que descreve todas as situações que existem quando dois ou mais comunicadores vêm de diferentes culturas. Assim, comunicação intercultural envolve diferenças culturais que transcendem diferenças raciais e étnicas.

É esse um momento sensível no qual se faz necessário adquirir um olhar pluricultural que permita um distanciamento da cultura em que se foi socializado para promover, por um lado, uma autorreflexão sobre a própria cultura e, por outro lado, uma tomada de consciência sobre a cultura do outro.

Assim sendo, a comunicação intercultural consiste no processo de interação comunicativa que inclui indivíduos e grupos que possuem diferenças culturais reconhecidas em suas percepções e formas de conduta que terminarão por afetar consideravelmente a forma e o resultado do encontro comunicativo. Em dito processo, diz-se que os indivíduos possuem habilidade para se relacionar e se comunicar de maneira efetiva quando possuem competência intercultural. Possuir competência intercultural, portanto, pressupõe saber desenvolver-se adequada e satisfatoriamente em situações de comunicação intercultural.

O conceito de competência intercultural foi apregoado por Byram (1997; 2008), em meados dos anos 1990, e sua proposta metodológica é centrada nas necessidades e capacidades pessoais de um aprendiz de língua estrangeira. Nesses termos, ele oferece um modelo de análise, segundo o qual existem cinco capacidades (saberes) formadoras da competência intercultural necessárias para uma comunicação exitosa: 1) a capacidade de adquirir conhecimentos interculturais: conhecimentos sobre sua cultura e a cultura do outro; 2) a capacidade de tomar atitudes favoráveis à comunicação intercultural: essa capacidade diz respeito às atitudes em relação ao novo; 3) a capacidade de interpretar e relacionar: a capacidade de interpretar documentos ou eventos de outra cultura, explicá-los e relacioná-los 
com os da própria; 4) a capacidade de descobrir e interagir: trata-se da capacidade de adquirir e utilizar conhecimentos e práticas da nova cultura; e 5) a capacidade de adquirir uma consciência cultural crítica: consiste na avaliação crítica dos conceitos, das crenças e dos comportamentos próprios e alheios.

Segundo esse mesmo autor, as primeiras quatro capacidades podem ser adquiridas por experiências próprias e reflexões sem a intervenção das instituições de ensino, no entanto, a última capacidade - a de adquirir uma consciência cultural crítica - deve ser ensinada em um contexto de sala de aula, obviamente, sem supervalorizar o ambiente escolar formal como único lugar de aquisição de consciência cultural crítica. Para ele, a sala de aula é também o ambiente em que se pode adquirir conhecimentos sobre os processos de interação intercultural.

Para Byram (1997; 2008), o desenvolvimento da competência intercultural está estreitamente relacionado ao conceito de competência comunicativa. Ele dispõe que a base para adquirir competência intercultural consiste em possuir competência comunicativa. Assim, antecedendo ao conceito de competência intercultural, está o de competência comunicativa (CC), que se configura como sendo uma das concepções mais significativas da Linguística Aplicada no que concerne à aquisição de segundas línguas (L2) e ensinoaprendizagem de LE.

Tal competência assume definidamente sua supremacia e contribui decisivamente para esboçar um quadro mais complexo do conjunto de conhecimentos necessários para se atuar comunicativamente de forma adequada e efetiva.

Desde que foi introduzida por Hymes, nos anos 1970, a definição de competência comunicativa constitui-se de diversos modelos, revisados ou reconstruídos pelos próprios criadores e demais teóricos, ainda assim, mesmo que muito já tenha sido dito, perece inesgotável a discussão acerca de tal construto.

Hymes (1972) considera que a competência linguística - conhecimento das regras gramaticais em seus níveis morfológico, sintático, fonético-fonológico e semântico - é uma competência reducionista, uma vez que não contempla elementos do contexto sociolinguístico. Nessa direção, ele pondera:

Há regras de uso sem as quais as regras gramaticais seriam inúteis. Do mesmo modo que as regras sintáticas podem controlar aspectos da fonologia e as regras semânticas, quiçá controlar aspectos da sintaxe, as regras dos atos de fala agem como fatores que controlam a forma linguística em sua totalidade (1972, p. 278). 
As regras dos atos de fala a que se refere Hymes (1972) consistem em saber quando falar, quando não falar, e sobre o que falar, com quem, onde e de que forma. Isso indica que a competência de nos comunicar mediante o uso da linguagem reside na habilidade de formar enunciados que, além de gramaticalmente corretos, sejam, antes de tudo, socioculturalmente adequados e comunicativamente efetivos.

O advento do conceito de competência comunicativa no horizonte dos estudos da linguagem não deve ser interpretado como uma mera complementação ou extensão do conceito de competência gramatical, uma vez que, especialmente, trata-se de uma mudança de hierarquia em relação ao conhecimento que se considera subjacente à capacidade de nos comunicar mediante o uso de uma língua: a competência gramatical, que até então havia ostentado um lugar privilegiado ou até mesmo exclusivo, passa agora a estar subordinada a um conceito maior, o de competência comunicativa e, assim, dividir esse novo lugar em igualdade de condições com outros tipos de conhecimento (HUELVA, 2009).

A maioria dos autores concorda que a competência comunicativa é um fenômeno complexo composto por uma série de elementos ou subdivisões e apresenta seus modelos analisados sob diferentes perspectivas. Ainda assim, todos esses enfoques se aliam, significativamente, ao considerar a importância do componente sociocultural na categorização de algumas subcompetências.

Para Miguel (2005), o componente sociocultural constitui-se dos princípios que permitem ao falante usar o código de modo adequado em qualquer situação de comunicação:

No componente sociocultural é onde se concentram todos os elementos que regem a
adequação: conjunto de informações, crenças e saberes, objetos e posições desses
objetos, modo de classificação, pressuposições, conhecimentos e atuações (rituais,
rotinas, etc.) socialmente pautados que confluirão em qualquer situação
comunicativa e que fará que esta seja adequada ou premeditadamente inadequada
(2005, p. 513, tradução nossa).

Segundo a autora, o termo adequação está intimamente relacionado ao conceito de uso e consiste em o falante saber utilizar os recursos e as convenções que a língua proporciona para se desenvolver adequadamente em todas as situações de uso que se apresentem. Também Kramsch (2009), em seu artigo O privilégio do falante intercultural, sugere que seria melhor substituir a pedagogia do autêntico - fazendo alusão ao obsoleto "falante nativo" - por uma pedagogia do adequado (KRAMSCH, 2009, p. 31, tradução nossa).

Para Huelva (2009), o domínio desses conhecimentos contribui para compreender as intenções comunicativas entre interlocutores em um determinado contexto. Nesses termos, 
possuir o domínio do conjunto de elementos socioculturais de determinada comunidade de fala pressupõe ter competência sociocultural.

A essas formas específicas de interação, Bakhthin (2000) denomina gêneros discursivos - formas-padrão intrinsecamente relacionadas à vida sociocultural que se constituem sócio-historicamente, de acordo com as práticas comunicativas e interacionais em que estão inseridos os falantes. Segundo Silva (2014), por se tratar de produtos sociodiscursivos, essas formas-padrão acompanham as transformações pelas quais passa a sociedade. Dessa forma, os "gêneros discursivos configuram respostas às necessidades comunicativas que se apresentam nas mais diversas esferas de atividades humanas" (p. 59).

Por definição, a (sub)competência sociocultural é a parte integrante da CC em que reside, principalmente, no conhecimento das formas particulares de realização de ações comunicativas de determinada comunidade de fala, ou, em outras palavras, a (sub)competência sociocultural capacita o falante a desempenhar funções linguísticas que são apropriadas ao contexto. Huelva (2009, prelo) a concebe assim:

De certa maneira poderíamos inclusive afirmar que se trata de uma competência que
opera sobre a competência linguística (ou seja, de uma espécie de meta-
competência). É a competência que permite ao falante utilizar uma determinada
língua relacionando a atividade linguística comunicativa com uns determinados
marcos de conhecimento próprios de uma comunidade de fala. Esses marcos podem
ser parcialmente diferentes daqueles de outras comunidades e englobam, de um
modo geral, três grandes campos: o das referências culturais de diversas ordens; o
das rotinas e os usos convencionais da língua; e o das convenções sociais e os
comportamentos ritualizados não verbais. É, para dizê-lo de uma maneira mais
simples, a competência que usamos para relacionar nossa língua com os outros
componentes que integram a realidade cultural e social da comunidade de fala a que
pertencemos.

\section{FORMAÇÃO E REFLEXÕES}

As indagações sobre a questão da construção da práxis no ensino de línguas estrangeiras (LE), passando pela formação dos profissionais de línguas (professores), têm sido preocupação constante dos Centros de Formação (graduação, pós-graduação, cursos de extensão, treinamento, aperfeiçoamento dentre outros) ao longo do século XX e do começo do século XXI. Nesse sentido, mostra-se essencial não esquecer que a capacidade de refletir sobre a prática é a mola propulsora para o desenvolvimento profissional.

A reflexão só emerge na vida de um professor (no caso de línguas estrangeiras, neste estudo) quando há uma possibilidade de abertura para entendê-lo como um profissional em constante desenvolvimento e formação. É importante salientar, conforme Alvarez (2009), que 
a formação completa de um professor não acontece somente durante o período de graduação, mas é um processo continuo de aprendizagem e reflexão.

Almeida Filho (1997), frequentemente, escolhe o uso de termos como "qualificado" e/ou "certificado" como referência ao professor titulado, já que, de acordo com este autor, graduar-se é apenas o reconhecimento institucional e uma formação inicial para o exercício profissional. Por conseguinte, é necessário que o professor de língua estrangeira (LE) seja visto como um profissional em formação contínua que precisa estar sempre se atualizando, não só para refletir em um mundo em constante mutação ou compreender essa fluidez das ideias sociopolíticas da atualidade, mas também para ser capaz de provocar mudanças na sua área de atuação, assim como em outros profissionais de línguas e nos alunos. Segundo Alvarez (2009, p. 2), a prática profissional competente "se constrói em torno do conhecimento na ação e seu desenvolvimento depende da reflexão em uso".

Assim essa reflexão vai depender de como se entende a relação com os alunos e de como se entende também a educação e o ensino. Ao ver esse processo a partir de uma concepção bancária, de acordo com Paulo Freire (1975), o professor "deposita" o conhecimento que possui na cabeça do aluno ao (re)transmiti-lo; tem-se assim este como cliente numa perspectiva de prestação de serviços. Contudo, se, ao invés de entender a educação e ensino como um sistema bancário, entendemos o ensino como troca entre aquele que ensina e aquele que aprende em uma situação de interação, na qual o professor aprende com os alunos e estes aprendem com o professor e com outros alunos, então não há um único prestador de serviços nem clientes porque todos são vistos como prestadores de serviços e todos são clientes uns dos outros, fazendo uso de uma metáfora capitalista. Para tal, não se deve esquecer que a capacidade de refletir sobre a prática é parte inerente para o desenvolvimento profissional.

Agora, adentrando no campo da prática reflexiva e dos sujeitos (professores e alunos) que interagem na e pela reflexão, partiremos do pressuposto de que todos os seres racionais conscientes são dotados de reflexão e assim defende-se o termo reflexividade segundo Libâneo (2006). Portanto, na concepção deste autor, a reflexividade é uma autoanálise sobre nossas próprias ações, que podem ser feitas sobre nossas próprias práticas ou de outrem, levando não só ao pensamento reflexivo, mas também às ações de mudanças de processos e de agir.

Tem-se na mesma linha de reflexividade Paulo Freire (1976), que traz uma definição do conceito baseado no processo ação - reflexão - ação e objetivo, o que traria mais consciência sócio-histórica e política aos participantes (professores e alunos). Dessa forma, 
a reflexão é só legítima quando nos remete sempre ao concreto, cujos fatos busca esclarecer, tornando assim possível nossa ação mais eficiente sobre eles. Iluminando uma ação exercida ou exercendo-se, a reflexão verdadeira clarifica, ao mesmo tempo, a futura ação na qual se testa e que, por sua vez, se deve a uma nova reflexão (FREIRE, 1976, p. 135).

Logo, o pensamento e a prática reflexiva no agir, refletir e (re)agir se tornam cíclicos e infinitos e surgem da mente como elementos capazes de julgar como cada passo deve ser tomado em cada situação particular, não havendo regras nem tempo para isso, pois tudo depende do contexto interacional em que eles ocorrem. Assim, a percepção é que irá guiar as diferentes ações reflexivas. "Uma prática reflexiva confere poder aos professores e proporciona oportunidades para o seu desenvolvimento", segundo Alvarez (2009 p. 7). O combate à insatisfação sentida por muitos profissionais de línguas (professores) com a sua preparação profissional que não contempla determinados aspectos da prática tem conduzido a movimentos de reflexão e de desenvolvimento do pensamento sobre as práticas.

Com o intuito de propiciar a reflexão e o empoderamento, os professores devem interagir com os seus alunos, aceitar suas sugestões e opiniões, construir junto com eles o significado social das suas práticas, investigando-as como oportunidades de desenvolvimento profissional que reforçam o pressuposto subjacente de que, ao desenvolvê-las, o ensinoaprendizagem pode ser melhorado.

É preciso que o professor de LE como agente transformador se conscientize de que deve, em sua prática pedagógica, recorrer a materiais diversos, como estudar os poetas que marcaram e marcam a cultura analisada, músicas, culinária, folclore, mitos, enfim, estudos que permitam ao aluno refletir sobre a cultura do outro, bem como acerca da sua própria cultura, levando em consideração, principalmente, a contextualização. Baseado nessas questões, Moita Lopes (2002, p. 194) acredita que

\begin{abstract}
a aula de línguas oferece uma possibilidade infinita de trazer conhecimentos outros para o foco de atenção, tendo, como fontes principais de orientação do professor, a adequação do aprendiz a esses conhecimentos e sua capacidade discursiva, embora, é claro, aquilo sobre o que se usa a linguagem em sala de aula, isto é, os conhecimentos acionados pelo professor, dependa, crucialmente, da sua visão de mundo, seus projetos políticos, crenças, valores, preconceitos (MOITA LOPES, 2002. p. 194).
\end{abstract}

Dentro dessa possibilidade de reflexão sobre o ensino-aprendizagem de LE, faz-se necessário permitir que o impulso, a intuição e a rotina se transformem em ações orientadas pelo pensamento crítico e, com isso, o entendimento mais aprofundado da relação entre os 
próprios comportamentos de ensino-aprendizagem e seus respectivos impactos sobre os alunos e sobre a instituição de ensino.

\section{ANÁLISES E CONSIDERAÇÕES FINAIS}

As análises e leituras ocorreram durante os anos de 2010-2014 com as LE (alemão, árabe, coreano, espanhol, esperanto, francês, hebraico, inglês, italiano, japonês, mandarim, russo e turco). Essas línguas são ofertadas a cada semestre no período da tarde e/ou noite e aos sábados (manhã e/ou tarde) nos campi da UnB nas regiões de Planaltina, Gama, Asa Norte e no pólo do Setor Comercial Sul (SCS), com duração média de três horas e vinte minutos por semana, inclusive aos sábados.

A escolha dos relatórios finais dos cursos livres de LE se deu pelo fato desse material ser um reflexo, na maioria das vezes, do fazer dos professores do UnB Idiomas, além de se configurar como sendo documentos oficiais da universidade no que tange ao processo de certificação da turma e do professor. Apesar de as aulas serem ministradas na língua-alvo, com foco na aquisição/aprendizagem dos alunos nas competências e habilidades em LE, o relatório final é redigido em português.

De forma aleatória, escolhemos, no mínimo, dois professores das LE ensinadas no UnB Idiomas durante o período de 2010-2014. Ressaltamos que, para o presente estudo, não fizemos distinção entre nativos e não-nativos, pois compreendemos que tal aspecto na globalização das línguas não é de muita importância no ensino-aprendizagem, como elucidado por Signorini e Cavalcanti (1998). Devido ao caráter institucional da função supervisor pedagógico, nos valemos também das observações das aulas para compor as análises desta pesquisa, segundo André (2005).

Após leituras de mais de cem relatórios e mais de duzentas horas de observações de aulas, percebemos que o esforço na formação continuada e os encontros constantes entre professores e supervisores acadêmicos no início de cada semestre, além de motivar e renovar as práticas dos professores de LE do UnB Idiomas, trouxeram aspectos didático-pedagógicos inovadores às aulas que se encontravam deficientes ou, até mesmo, desprovidas completamente de tais aspectos. Entre os professores beneficiados, no que tange às práticas inovadoras de ensino de LE e interculturalidade, destacamos os de hebraico, mandarim, turco, árabe e esperanto. Percebido isso, propusemos atividades em duplas nas quais professores menos experientes formaram pares com professores com bastante vivência em sala de aula, não necessariamente da mesma LE ensinada no UnB Idiomas, para que juntos, de forma 
colaborativa, chegassem ao entendimento dos aspectos culturais no ensino-aprendizagem de LE como proposto por Alvarez (2009) e Silva (2014).

Outro ponto positivo se deve ao fato de que os relatórios, na medida do possível, terem sido lidos e revisados na companhia dos professores de LE pesquisados. Assim tivemos, além das leituras e das observações, conversas profícuas no sentido de trazer mais suporte teórico e prático no entendimento da interculturalidade e práticas reflexivas para guiar um fazer pedagógico inovador no ensino-aprendizagem dos professores de LE no UnB Idiomas, como coadunados por Byram (2008) e Huelva (2009).

A dificuldade a ser superada, após as análises, observações e conversas, encontra-se relacionada diretamente a alguns professores de LE (turco, árabe, mandarim, por exemplo), pelo de eles não perceberem que a língua perpassa a cultura e vice-versa e, também, que a língua é mais do que elementos estruturais. Portanto, sugerimos mais leitura, mais observações de outros professores experientes no UnB Idiomas, assim como um acompanhamento mais constante com a supervisão acadêmica.

Ademais, os relatórios finais de cursos livres de LE do UnB Idiomas se mostraram como instrumentos satisfatórios para registro oficial e pedagógico no tocante ao entendimento da competência sociocultural, interculturalidade, práticas reflexivas e inovadoras em sala de aula. Contudo, esses conceitos e atitudes em sala de aula de LE devem ser perenes, haja vista que o profissional de línguas, no caso específico deste trabalho dos professores de LE do UnB Idiomas, está em constante formação e precisa refletir as demandas atuais da sociedade, colaborando, assim, para a formação de cidadãos do mundo mais tolerantes e pacíficos com o caleidoscópio cultural no qual vivemos.

\section{REFERÊNCIAS}

ALMEIDA FILHO, J.C.P. Tendências na Formação Continuada do Professor de Língua Estrangeira. In: Ensino e Pesquisa, v.1, APLIEMG, 1997.

ALVAREZ, M. L. O. Reflexão sobre teoria e prática na formação do profissional de línguas. Disponível em:

$<$ http://www.let.unb.br/mlortiz/images/stories/professores/documentos/artigos/artigos_pdf/Ar tigo_sobre_reflexao_definitivo.pdf $>$ acesso em 26 de setembro de 2016.

ANDRÉ, M. D. A. Etnografia da prática escolar. 12. ed. Campinas, São Paulo: Papirus, 2005.

BAKHTIN, M. Os gêneros do discurso. In: Estética da criação verbal. Tradução de Paulo Bezerra. 3. ed. São Paulo: Martins Fontes, 2000. p. 262-335.

BENNETT, M. J. Basic Concepts of Intercultural Commnunication: Paradigms,

Principles \& Practices. Oregon; Intercultural Press, USA, 2013. Disponível em

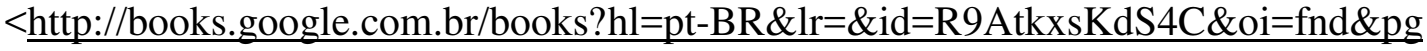


$=$ PA7\&dq=related:34hPGy9Se_IJ:scholar.google.com/\&ots=IDyV02XJIE\&sig=mPswUx3n V21vUazmeM_SvzSWqC8\#v=onepage\&q\&f=false $>$ acesso em 26 de julho de 2016.

A developmental approach to training for intercultural sensitivy. In: International Journal of Intercultural Relations (2) 10. S/l. 1986.

Intercultural communication: A current perspective. In M. J. Bennett (Ed.), Basic concepts of intercultural communication: A reader. Yarmouth, ME: Intercultural Press, 1998. BYRAM. M. Teaching and Assessing Intercultural Comunicative Competence. England, Multilingual Matters, 1997.

From Foreign Language Education to Education for Intercultural Citizenship: Essays and Reflections. England, Multilingual Matters, 2008.

DÍAZ, G. C. Los contenidos culturales. En Vademécum para la formación de profesores. Enseñar español como segunda lengua (L2)/lengua extranjera (LE). SÁNCHEZ LOBATO, J.; I. SANTOS GARGALLO (Dir.). Madrid, SGEL, 2005.

- La dimensión cultural en la enseñanza/aprendizaje de lenguas extranjeras. En (Dir.). Lenguas para abrir camino. Madrid: MECD, 2002, pp. 193-226. Disponível em $<$ http://sedll.org/es/admin/uploads/congresos/15/act/156/Lorente,_Pilar_y_otra.pdf> acesso em 31 de julho de 2016.

ELHAJJI. M. Comunicação Intercultural: prática social, significado político e abordagem científica. Em Revista da Associação Nacional dos Programas de Pós-Graduação em Comunicação. Agosto de 2006 - 2/16. Rio Janeiro, UFRJ, 2006. Disponível em $<$ http://www.compos.org.br/seer/index.php/e-compos/article/viewFile/86/86> acesso em 29 de setembro de 2016.

FREIRE, P. Pedagogia do oprimido. Rio de Janeiro: Paz e Terra, 1975. $\overline{1976}$

Ação cultural para a liberdade e outros escritos. Rio de Janeiro: Paz e Terra,

GUDYKUNST, W. B. Intracultural communication. Introduction. In: (Org.) Handbook of international and intercultural communication. Thousand Oaks, London, New Delhi: Sage Publications, 2002. Disponível em $<$ http://seer.bce.unb.br/index.php/les/article/viewFile/1227/884> Acesso em 11 de abril de 2016.

HALL, E. T. Más allá de la cultura. Colección Punto y Línea. Barcelona: Gustavo Gili, 1978.

HUELVA, E. U. Cultura e competência sociocultural no ensino de espanhol como língua estrangeira. (prelo), 2009.

HYMES, D. H. On Communicative Competence In: J. B. Pride and J. Holmes (Eds) Sociolinguistics. Selected Readings. Harmondsworth: Penguin, 1972.

REVISTA X, Curitiba, volume 12, n.1, p.,2017

KRAMSCH, C. El privilegio del hablante intercultural. En: BYRAM, M.; FLEMING, M. (Eds.). Perspectivas interculturales en el aprendizaje de idiomas. Madrid: Cambridge University Press, 2009.

. Language and culture. Oxford: Oxford University Press, 2001.

LIBÂNEO, J. Reflexividade e formação de professores: outra oscilação do pensamento pedagógico brasileiro? In: PIMENTA, S.G \& GHEDIN, E. (Org.) Professor reflexivo no Brasil. São Paulo: Cortez, 4a. Ed., 2006.

MIGUEL, L. Lengua y cultura desde una perspectiva pragmática: algunos ejemplos aplicados al español. In: Revista Electrónica de Didáctica / Español lengua extranjera. n. 2. S/1: 2008. Disponível em $<$ http://redined.mecd.gob.es/xmlui/bitstream/handle/11162/72231/00820083000346.pdf?sequ

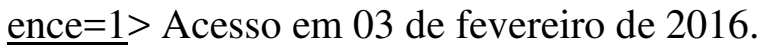


La subcompetencia sociocultural, In: SÁNCHEZ, L. J.; SANTOS, G. I. (Eds.) Vademécum para la formación de profesores. Madrid: SGEL, 2005.

MOREIRA, D. A. O método fenomenológico na pesquisa. São Paulo: Pioneira Thomson, 2002.

RIVERS, W. M. Speaking in Many Tongues: Essays in foreign-language teaching. Cambridge, Cambridge University Press. 1983. Disponível em

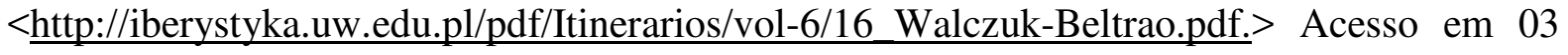
de junho 2016.

SAMOVAR, L. A.; PORTER, R. E. Intercultural Communication: A Reader. BelmontCalifornia: Wadsworth Publishing Company, 1972.

Company, 1998.

Communication between cultures. Belmont-California: Wadsworth Publishing

SIGNORINI, I.; M. C. CAVALCANTI (Orgs.). Lingüística Aplicada $e$ Transdisciplinaridade: Questões e Perspectivas. Campinas: Mercado de Letras, 1998.

SILVA, E. D. A-TUA-AÇÃO: O texto teatral, o corpo e a voz como mediadores da apropriação da oralidade no ensino-aprendizagem de LE (Francês). 106f. Dissertação de mestrado (Mestrado em Linguística Aplicada). PPGLA/LET/UnB. Brasília, 2014. Disponível em $\quad<$ http://repositorio.unb.br/bitstream/10482/17176/1/2014_EduardoDiasdaSilva.pdf $>$ acesso em 26 de julho de 2016.

VEZ, J. M. Aportaciones de la Lingüística. En Vademécum para la formación de profesores. Enseñar español como segunda lengua (L2)/lengua extranjera (LE). SÁNCHEZ LOBATO, J.; I. SANTOS GARGALLO (Dirs.). Madrid: SGEL, $2005 . \quad$ p.140. 